\title{
REALIDADE LATINO AMERICANA: RELATO DA VIAGEM PARA ARGENTINA E CHILE
}

\author{
Fabiana Rita Dessotti \\ Universidade Federal de SãoPaulo \\ frd@uol.com.br \\ Richard Alves Sales \\ Universidade Federal de São Paulo \\ richardsales029@gmail.com
}

\begin{abstract}
Resumo
Este texto apresenta um relato da viagem para a Argentina e Chile, realizada em julho de 2017, como parte do Programa de Extensão Realidade Latino Americana. Este Programa propõe o estudo, pesquisa e difusão de conhecimento sobre um ou mais países do continente em cada ano. No ano de 2017, constituiu- se um grupo de 30 integrantes que se envolveu em um processo de formação sobre os dois países, que culminou com uma viagem à Argentina e Chile. A viagem teve duração de 17 dias, envolvendo uma intensa agenda de encontros, eventos e debates, com a participação de diversas lideranças políticas, sindicais e de militâncias que lutaram contra a repressão e pela democracia. Os encontros contribuíram para o processo de formação do grupo, no sentido de que convergiram para mostrar os impactos das ditaduras nos Estados e na vida da população. A viagem de pesquisa contribuiu para a elevação da análise prática de diferentes governos e principalmente da luta social não só de uma nação, mas de um sentimento latino que propaga a independência e a soberania de países que já passaram e passam por grandes mazelas em suas histórias.
\end{abstract}

Palavras-chave: Programa Realidade Latino Americana. Argentina. Chile. Viagem técnica de pesquisa. Economia. Política.

\section{LATIN AMERICAN REALITY: REPORT ON THE TRIP TO ARGENTINA AND CHILE}

\begin{abstract}
This text presents a report on the trip to Argentina and Chile, held in July 2017, as part of the Latin American Reality Extension Program. This Program proposes the study, research and diffusion of knowledge about one or more countries of the continent in each year. In the year 2017, a group of 30 members was formed and was involved in a process of formation about the two countries that culminated in a trip to Argentina and Chile. The trip lasted 17 days, involving an intense agenda of meetings, events and debates, with the participation of several political leaders, trade unionists and militants who fought against repression and for democracy. The meetings contributed to the process of formation of the group, in the sense that they converged to show the impacts of dictatorships in the States and in the life of the population. The research trip has contributed to the elevation of the practical analysis of different governments and mainly the social struggle not only of one nation, but of a Latin sentiment that propagates the independence and sovereignty of countries that have already gone and go through great illnesses intheir histories.
\end{abstract}

Keywords: Latin American Reality Program. Argentina. Chile. Technical Research Trip. Economy. Policy. 


\section{REALIDAD LATINOAMERICANA: RELATO DEL VIAJE A ARGENTINA Y CHILE}

\section{Resumen}

Este texto presenta un relato del viaje a Argentina y Chile, realizado en julio de 2017, como parte del Programa de Extensión Realidad Latinoamericana. Este programa propone el estudio, investigación y difusión de conocimiento sobre uno o más países del continente cada año. En el año 2017 se constituyó un grupo de 30 integrantes que se involucró en un proceso de formación sobre los dos países que culminó con un viaje a Argentina y Chile. El viaje tuvo una duración de 17 días, involucrando una intensa agenda de encuentros, eventos y debates, con la participación de diversos líderes políticos, sindicales y de militancias que lucharon contra la represión y por la democracia. Los encuentros contribuyeron al proceso de formación del grupo, en el sentido de que convergieron para mostrar los impactos de las dictaduras en los Estados y en la vida de la población. El viaje de investigación contribuyó a la elevación del análisis práctico de diferentes gobiernos y principalmente de la lucha social no sólo de una nación, sino de un sentimiento latino que propaga la independencia y la soberanía de países que ya pasaron y pasan por grandes males en sushistorias.

Palabras clave: Programa Realidad Latinoamericana. Argentina. Chile. Viaje técnico de investigación. Economía. La política. 


\section{INTRODUÇÃO}

O objetivo deste texto é descrever, em perspectivas mais sensitivas, o olhar de dois dos membros do Programa de Extensão Realidade Latino Americana sobre a viagem técnica de pesquisa realizada na Argentina e no Chile, em julho de 2017.

O Programa Realidade Latino Americana nasceu em 2014 como uma proposta de extensão, no Departamento de Relações Internacionais da UNIFESP (Universidade Federal de São Paulo). O Programa se articula a partir dos seguintes elementos: i) atividades de formação preparatórias; ii) visitas e entrevistas nos países pesquisados; iii) a divulgação dos resultados do processo, por meio de debates públicos e publicações, concretiza a articulação entre ensino, pesquisa e extensão que deve caracterizar as atividades das instituições públicas de ensino superior.

Trata-se, portanto, de um programa de múltiplas implicações acadêmicas, dentre as quais destacam-se: i) o estudo teórico e o contato vivencial com a realidade de diferentes países latino-americanos; ii) a possibilidade de aprender com especialistas no Brasil e nos países visitados; iii) o contato com organizações sociais de diferente natureza (direitos humanos, movimentos populares, organizações indígenas, entre outras) e personalidades políticas, propiciando uma experiência de aprendizagem que transcende o ambiente acadêmico; iv) uma vivência de estudo e pesquisa interdisciplinar e interinstitucional; v) possibilidade de aprendizagem intensiva, por meio da convivência extra-acadêmica com professores e pós-graduandos ao longo do processo; vi) uma experiência de construção coletiva do conhecimento, em contraste com a pesquisa individual; e vii) elaboração dos resultados do processo por meio da organização de eventos públicos ou publicações dosresultados.

Em 2017, a partir da constituição de grupos multidisciplinares e pluri institucionais de estudantes em diferentes estágios da formação acadêmica, além de professores e interessados em América Latina, organizou-se o Projeto Argentina/Chile. Partiu-se do estudo da ditadura nesses países (Argentina e Chile), para refletir sobre os limites da transição e os dilemas da atualidade. O problema de fundo proposto foram os entraves para conciliar capitalismo e democracia no capitalismo dependente. Foram propostos os seguintes objetivos específicos: i) problematizar a noção difundida do Chile como a experiência de neoliberalismo que deu certo; e ii) analisar a experiência dos governos Kirchner na Argentina, estabelecendo paralelos com as gestões petistas no Brasil.

O processo de formação deu aos participantes uma profunda compreensão sobre 
o passado de lutas sociais e governos autoritários desses territórios. Temas como a ditadura de Pinochet no Chile e o processo ditatorial na Argentina foram essenciais para a investigação e o entendimento dos encontros e palestras a que os participantes foram expostos. Temas atuais como os governos progressistas recentes, kirchneristas na Argentina e a antiga presidência de Michele Bachelet no Chile, foram alvos de estudos e ponderações também para com a realidade brasileira.

\section{A viagem}

A viagem teve duração de cerca de 17 dias, sendo 7 dias no Chile e um traslado até Buenos Aires de 2 dias, com direito a parada em Mendoza. Na capital Argentina o grupo permaneceu por mais 7 dias. Nos dois países a agenda de encontros, eventos e debates foi intensa e atendeu ao propósito de formação do grupo, nos encontros reuniramse diversos acadêmicos, lideranças políticas e sindicais, além de militâncias que lutaram contra a repressão e pela democracia.

\section{Chile}

O Chile proporcionou uma visão bastante acalorada da potencialidade do neoliberalismo em um país do terceiro mundo, a diferença entre a noção de direito social e privado em comparação com o Estado brasileiro foi um dos maiores choques de realidades dos participantes. Por meio de uma narrativa cotidiana baseada na agenda de eventos, este relato caminhará ao encontro da perspectiva natural encontrada pelos membros do grupo ao encarar a realidade chilena.

O primeiro dia em Santiago do Chile, 1 de julho de 2017, reservou ao grupo dois encontros, o primeiro tratou do tema "Chile e integração regional", com Consuelo Silva - Coordenadora GT Integração Regional da CLACSO (Conselho Latino Americano de Ciências Sociais), e o segundo tratou a "Economia política da Concertación", com Claudio Lara, ambos economistas. O economista Cláudio apresentou algumas reflexões gerais sobre o modelo econômico chileno e sobre o Chile no contexto da crise econômica global. Já a Consuelo falou sobre a estratégia comercial e o processo de reprimarização da economia chilena.

A fala de Consuelo, mais técnica, permitiu aos participantes enxergarem uma abordagem mais governamental e diplomática, que demonstra a importância da abertura econômica chilena possui na sua própria sociedade. Ostentar o papel de país mais livre economicamente da América Latina, e um dos mais livres do mundo, demonstrou um grande impacto à integração do país, que ao fim e ao cabo, parece ser pautado por 
processos de integração bilateral com diversos países, sendo pouco importante na conjuntura neoliberal o sentimento de pertencimento a uma região. A discussão sobre a inserção internacional chilena mostrou a relevância do debate sobre a integração dos países latinos.

A economia política da Concertación resultou em processos que tinham como intenção a recuperação da força democrática e o significado de direito social dentro do país. Entretanto, a perspectiva real é de que o governo que pretendia consertar as mazelas realizadas na ditadura não foi capaz de realizar tais feitos, e proporcionou ao país a manutenção de políticas neoliberais de forma com que parecessem menos agressivas. Nesse viés, o grupo teve seu primeiro impacto com os problemas chilenos referentes ao peso da ditadura e dos governos democráticos depois dela, o que também já havia sido discutido no processo de formação dos participantes.

A caminhada por Santiago, que demasiadamente impressionava o grupo por sua beleza arquitetônica e sua conservação social, levou aos encontros que faltavam para encerrar o primeiro dia da programação. Este, provavelmente, foi um dos que mais impactaram o grupo, uma conversa quase que de amigos com 3 senhores que, aparentemente, resumem seus dias atuais em uma vida idosa como de qualquer outro senhor, mas que apresentam um passado de muita militância política. Orlando Caputo, economista, diretor da Companhia Nacional do Cobre - $\mathrm{CODELCO}^{1}$, durante o governo Allende $^{2}$, e Jacques Chonchol, ministro da agricultura do governo Allende, fizeram uma longa apresentação, juntamente com Oscar Torres que havia sido segurança pessoal de Allende. Esta apresentação foi de grande impacto aos participantes, uma sessão de horas em que a sabedoria da idade dialogou com a juventude em temas que permeavam a dependência chilena em relação ao Cobre e a reforma agrária realizada pelo país, assuntos importantes para entender a conjuntura de desindustrialização nacional sofrida no período.

A grande experiência que pode ser extraída do primeiro dia no Chile foi que mesmo perdendo em suas lutas políticas, em sua época de maior auge, os 3 senhores não deixaram de exercer sua militância e sua luta política inerente ao desenvolvimento de qualquer nação e de qualquer cidadão comprometido com sua ideologia.

\footnotetext{
${ }^{1}$ CODELCO é a empresa de mineração estatal do Chile, responsável por grande parte da produção de riqueza no país.

${ }^{2}$ Salvador Allende foi o político chileno que tomou o golpe militar ditatorial em 1973 e que tinha como plataforma o "Socialismo por vias legais".
} 
Acordar com a visão da Cordilheira dos Andes e com o grupo unido em um mesmo Hostel contribuía para a aproximação e amadurecimento do projeto. $\mathrm{O}$ segundo dia reservou uma manhã livre que pode ser aproveitada de diferentes formas pelos participantes, sendo o Cerro San Cristóban a opção mais visitada. A visita ao Cerro permitiu que os participantes tivessem uma visão ampla e reveladora de Santiago, mostrando suas incríveis belezas, mas também suas mazelas.

A atividade realizada na parte da tarde foi com Sergio Grez, um historiador, especialista na história da constituição chilena. O especialista fez um apanhado histórico da constituição chilena, destacando as características da constituição atual, que foi implementada em um período não democrático do país, apresentando os seus elementos neoliberais e reforçando a necessidade de uma reforma constituinte. O impacto com que o estado de exceção transcende o poder democrático e se instalou como política de Estado surpreendeu o grupo, as comparações com as diversas ditaduras do Cone Sul que passaram por um processo de redemocratização baseado em novas constituintes alertaram ao grupo sobre uma profunda conexão entre a força do estado de exceção e a intensidade do neoliberalismo presente na sociedade chilena, sendo um extremamente relacionado ao outro.

No terceiro dia, o raciocínio do grupo ia maturando ideias cada vez mais consolidadas na sociedade chilena, a presença do individualismo e ao mesmo tempo o progressismo das tomadas de decisões do governo Bachelet, juntamente com os protestos secundaristas, mostrava uma sociedade confusa e indecisa sobre a luta histórica e o passado ideológico de seu país. Isso foi avaliado no encontro com 2 historiadores do IDEA - Faculdade de Ciências Sociais da Universidade do Chile, Rolando Alvarez (historiador, especialista na história do Partido Comunista do Chile) e Pablo Rubio (historiador, especialista na história das direitas chilenas), na discussão sobre o passado e sobre o presente das esquerdas e direitas chilenas.

Na parte da tarde, o grupo realizou uma visita à CEPAL-Comissão Econômica para América Latina, o que permitiu uma imersão no quadro geral das economias latinoamericanas, além de um tour que impressionou os participantes pela estrutura do local.

Durante a noite, a atividade demonstrou a força do movimento campesino, durante e depois da reforma agrária realizada por Allende, bem como a reestruturação dessa força, principalmente das mulheres, a partir da formação do movimento feminista urbano. O encontro foi promovido com o objetivo de tratar "Feminismo chileno: campo y ciudad" e foi coordenado por Alice Muñoz, uma ativista rural, e Macarena Castañera, integrante do movimento NiUnaMenos. O debate girou em torno da importância de 
reflexões sobre a reforma agrária realizada pelo governo Allende e os preconceitos atuais no país, que ostenta o maior índice de desenvolvimento humano da América Latina e um dos piores índices de desigualdade social.

No dia seguinte o grupo fez uma visita a Villa Grimaldi, monumento nacional instalado onde funcionava o Quartel Terranova, um centro secreto de sequestro, tortura e extermínio da ditadura militar do governo Augusto Pinochet. A visita foi guiada por Magdalena Garcés, advogada de direitos humanos, que finalizou a atividade apresentando alguns elementos sobre a luta pela memória, verdade e justiça no Chile. A visita a um local destinado a torturas e mortes demonstrou a violência deliberada e a perseguição institucional ao partido comunista chileno. A presença do grupo diante de um local de aprisionamentos forçados e torturas, que atualmente é um museu que revive o passado sangrento da ditadura, deu a dimensão do que foi esse período na história do Chile.

Os eventos da tarde e da noite do mesmo dia focaram em realizar debates sobre o atual contexto do neoliberalismo chileno, mais especificamente as questões relacionadas ao mundo do trabalho e a educação. José Luis Ugarte, advogado especialista em direito do trabalho e Marco Kremerman, economista da Fundación Sol, especialista no sistema previdenciário chileno, dirimiram as dúvidas do grupo a respeito do impacto das políticas neoliberais no Chile sobre o mundo do trabalho. Falou-se sobre o cotidiano dos trabalhadores chilenos e colocou-se o grupo em contato com uma série de conceitos que não são avaliados da mesma forma no Brasil, como o pleno emprego, a rotatividade dos trabalhadores e as condições de trabalho, entre outros. Traçou-se um sistema individualista que recruta a parte pobre da população a um regime de inconstância de cargos, competitividade surrealista e alto número de pessoas com necessidade de renda complementar, ou seja, problemas que também podem ser observados em outros países latinos, mas que tem diferentes formas de difusão dentro do Estado.

O sociólogo chileno Victor Orellana, especialista em Educação, da Fundación Nodo XXI, apresentou os principais elementos sobre o sistema educacional chileno. Revelou-se um mundo de grande impacto para o grupo, que em sua maioria, via a educação como um direito social garantido. A distribuição de dívidas que o Estado proporciona à sua própria população, com um sistema de vouchers e financiamento do ensino em parceria com a iniciativa privada foi um importante tema para a reflexão do grupo.

O dia seguinte, 5 de julho, também trouxe elementos importantes para reflexão 
do grupo. O grupo deixou a beleza de Santiago e tomou contato com a aparência mais conturbada e pobre de Valparaíso. Na cidade costeira do pacífico, que permite grande parte do escoamento de produção chilena, se observou uma dinâmica social envolta em cultura mais popular e carente. O grupo visitou o Instituto de Geografia de Valparaíso e conversou com: Pablo Mansilla Quiñones, geógrafo, especialista em conflitos territoriais e resistência ao modelo extrativista; Paola Bolados, geógrafa, especialista em conflitos ambientais de Valparaíso e resistência ao modelo extrativista; e Maria Ignacia Pontes, doutoranda em geografia, que estuda os impactos da IIRSA sobre os povos da cordilheira. Os encontros se caracterizaram por um aspecto geográfico de análise das condições territoriais e dos acessos limitados da população às suas próprias riquezas naturais, bem como evidenciou o ataque extrativista dos grandes interesses corporativos.

Logo depois, o grupo partiu para conhecer o Congresso Nacional chileno, que fica em Valparaíso devido ao bombardeamento do congresso anterior na época do golpe militar em Santiago, sua transferência também ajudou na distância dos parlamentares em relação ao governo central ditatorial em Santiago. Nesta visita o grupo se encontrou com um jovem líder político, Gabriel Boric, que foi eleito e ganhou público com sua militância no movimento estudantil secundarista, o mais forte dos movimentos de protestos no Chile. A conversa possibilitou ao grupo reflexões sobre a nova ordem de aceitação das políticas neoliberais, principalmente de educação em nível superior. $\mathrm{O}$ endividamento dos estudantes no sistema de privatização do ensino no Chile não mais aparece como algo aceitável e esta nova forma de lidar com o aparato neoliberal, construído pela ditadura e perpetuado por erros da concertación, envolve o aparecimento de novos líderes e o fortalecimento dos protestos estudantis no cenário político.

Como última atividade em Valparaíso, no fim da tarde o grupo se reuniu com Santiago Aguiar Carvajal, ex militante do MIR - Movimiento de la Izquierda Revolucionaria, ativista da cultura e fundador do Centro Cultural Playa Ancha. Santiago apresentou as principais características do centro e os aspectos históricos do movimento que levou a sua criação. O grupo pode visitar e refletir sobre o poder de revolução da arte em meio à vulnerabilidade social da área, que abrigava até um antigo presídio durante a ditadura.

O último dia de atividades no Chile foi composto por encontros que tratavam sobre a política atual chilena e os direitos sociais que comumente são disputados pela população com as grandes corporações. O primeiro encontro se dispôs a debater o 
movimento "Frente Amplio" com integrantes de diferentes ramos da esquerda e que se aglomeram em um mesmo movimento para alcançar representatividade social maior e fortalecer o movimento político de esquerda. De certa forma, a experiência do Frente Amplio impactou o grupo à reflexão sobre a falta de um movimento de fortalecimento das esquerdas em território brasileiro e na diferença entre a renovação da política chilena do ponto de vista dos movimentos populares em relação ao Brasil. Foram entrevistados representantes de Rovolucion Democratica, Nueva Democracia, Movimiento Autonomista e Isquierda Autonóma.

A última atividade do grupo debateu a resistência territorial no campo e na cidade e exemplificou como direitos básicos, tal qual o direito a água, não é livre, com Rodrigo Mudança da MODATIMA - Movimiento de Defensa por el Acceso al Agua, la Tierra y la protección del Medio ambiente. O difícil acesso de pequenos produtores e da população urbana e a disputa com as grandes corporações pelo direito ao uso deste bem comum demonstra que a sociedade chilena parte de uma visão altamente isolacionista, característica triunfante do neoliberalismo.

Nessa intensa agenda e períodos de exacerbação do raciocínio plural de ideias e constatações acerca do modelo chileno o grupo reuniu crescimento intelectual, choque de culturas e conceitos ou até mesmo pré-conceitos, bem como se desvinculou de muitos pressupostos para mergulhar na realidade social chilena e na luta latinoamericana que se desenvolveu naquele país. O mesmo ocorreu na Argentina, cuja agenda foi de intensa troca e muito mais proximidade com a realidade brasileira.

\section{Argentina}

A agenda de atividades na Argentina teve sua diferença bem salientada em relação à do Chile, a relação com os sindicatos visitados e as semelhanças com os sistemas brasileiros estiveram mais presentes nas discussões do grupo.

O grupo chegou à capital argentina no dia 09 de julho de 2017, dia da independência do país, se viam muitas bandeiras nas ruas e uma metrópole calma e tranquila, sem muitos conflitos sociais.

A primeira atividade, no dia 10 de julho, foi com Julio C. Gambina, economista, diretor do Instituto de Estudios y Formación de la CTA-Autónoma e presidente da Fundación de Investigaciones Sociales y Políticas. A conversa de apresentação deste sindicato, que é um dos mais importantes na Argentina, possibilitou analisar grandes diferenças entre o sistema sindical brasileiro e o argentino, bem como pensar a respeito do governo Macri e de suas políticas mais liberalizantes. Pela tarde, a conversa foi 
muito parecida, só que desta vez aconteceu na própria CTA Autónoma com outros diretores que deram depoimentos das mais diversas condições laborais e sociais do país, que vêm sendo criticada cada vez mais.

No dia seguinte, ocorreu uma das mais importantes atividades realizadas na Argentina, o encontro com o Movimiento del Ocupantes e Inquilinos (MOI) y del Movimiento Territorial de Liberación (MTL). Esses movimentos fizeram uma confortável reunião com o grupo cedendo informações diversas sobre toda a luta política urbana pelo acesso à moradia na capital argentina e como o governo lida com isso, permitindo aos participantes maiores compreensões e reflexões sobre a política de acesso à moradia e a organização desses movimentos em cooperativas de trabalhadores para a construção de apartamentos a serem ocupados. O grupo visitou um desses locais onde as cooperativas atuam, com trabalhadores da própria comunidade para a construção de moradias para os cooperativistas e pessoas sem teto, a cooperação do governo se restringe ao fato de conceder autorização para construção no local por meio de um programa de cadastro de recuperação de locais e terrenos de possível uso para moradias, entretanto, a luta central pertence aos trabalhadores. Na visita feita pelo grupo, a convicção com que os organizadores dos movimentos têm com esse projeto e sua estruturação física, foi possível observar que é um programa que funciona, buscando estritamente o coletivismo com bases em ideologias socialistas. Neste ponto fica clara a inflexão do programa como projeto de extensão e seu fortalecimento do aprendizado em classe das diferentes formas de convívio e planos socioeconômicos aplicados à realidade concreta.

O dia 12 de julho foi marcado pela visita que o grupo fez até a periferia de Buenos Aires, um subúrbio localizado a 1h30min de trem da capital chamado José C. Paz, nele se encontra uma universidade fundada recentemente (2009) e que compõe um polo de estudos em meio a uma área de extrema fragilidade social. $\mathrm{O}$ debate do grupo ocorreu com alguns integrantes da Universidade e com duas mulheres que integravam o movimento piqueteiro, que realizavam piquets na conturbada crise de 2001 , em que a Argentina chegou ao caos político, social e econômico. As mulheres apresentaram um discurso emotivo e apaixonado pela sua posição ideológica e impressionaram o grupo, principalmente em reflexões que faziam sobre os Kirchner que eram possíveis de se comparar ao Lulismo no Brasil. Foi também um importante momento do grupo para entrar em contato com duas pessoas que participaram ativamente no papel de ajudar comunidades em sofrimento na crise de 2011, e entender um pouco mais sobre esse período que mudou completamente a história argentina. 
O penúltimo dia de agenda em Buenos Aires foi marcado pela passeata das "Madres de Mayo", na qual alguns alunos conseguiram comparecer. Esse evento é uma lembrança constante das mães que perderam seus filhos na ditadura argentina, e que pregam uma constante luta contra o autoritarismo e modelos econômicos que extinguem os direitos sociais e legitimam a desigualdade como fruto natural da essência social.

Durante a noite, o grupo se reuniu no Hostel em que estava hospedado e fez um debate interno para refletir e organizar tudo o que havia sido extraído daquela experiência até o momento. Os assuntos que mais chamaram atenção se voltavam ao neoliberalismo chileno de forma agressiva sobre todos os direitos sociais, principalmente educação, sistema laboral e o direito água. Sobre o que havia sido visto na Argentina até aquele momento, os principais fatos que chamaram atenção no país vizinho foram as semelhanças com o Brasil e as comparações possíveis entre os governos progressistas e as desigualdades e crises que avançaram sobre os dois países. O alto número de sindicatos, a pobreza aparente nas ruas e o caminho para governos de cunho neoliberal marcaram as análises dosparticipantes.

Assim, a viagem técnica de pesquisa chegou ao último dia com dois eventos, pela manhã o grupo partiu para um encontro sobre o debate dos direitos humano. O grupo visitou CELS - Centro de Estudios Legales y Sociales e a discussão transitou pela história Argentina e suas interrupções democráticas, que foram várias, e principalmente pela ditadura que se estendeu de 1976 a 1983. A ditadura argentina e suas agressões aos direitos humanos também foram fundamentais para o grupo entender os reflexos desse processo no desenvolvimento das políticas neo liberalizantes dos anos 90 no governo de Carlos Menem, que trouxeram problemas e muita miséria.

Por último, a atividade final da viagem foi uma visita ao Hotel Bauen, um lugar organizado e mantido pelos trabalhadores em cooperativismo, ou seja, em que os meios de produção estão nas mãos dos trabalhadores. A atividade se deu em uma roda de conversa em que a história e a administração cotidiana foram apresentadas ao grupo de forma a desenvolver um pensamento crítico sobre as possibilidades e alternativas ao comum modo de patronato consolidado na sociedade atual.

\section{CONSIDERAÇÕES FINAIS}

Sendo assim, a viagem técnica de pesquisa do Programa de Extensão Realidade Latino Americana contribuiu para a elevação da análise prática de diferentes governos e principalmente da luta social não só de uma nação, mas de um sentimento latino que propaga a independência e a soberania de países que já passaram e passam por grandes 
mazelas em suas histórias. Chile e Argentina representaram sociedades que ostentam melhores indicadores sociais na América Latina, porém ainda estão longe das sociedades desenvolvidas. A experiência e o estudo realizado elevaram o grupo de estudantes, professores e outros a dar um passo à frente na luta latina americana, pois todo o aprendizado e as contestações referidas aos pressupostos e à própria ideologia dos participantes são motivos de debate e avanço na produção científica do conhecimento. A contribuição social e a coleta de resultados da viagem são parte de frutos referentes ao empenho e dedicação de todos a esse projeto. 